\title{
Nasal Cavity and Paranasal Sinuses Cancer cM0 TNM Finding v8
}

National Cancer Institute

\section{Source}

National Cancer Institute. Nasal Cavity and Paranasal Sinuses Cancer cMo TNM Finding v8. NCI Thesaurus. Code C133069.

Nasal cavity and paranasal sinuses cancer without evidence of distant metastasis. (from AJCC 8th Ed.) 